\title{
CONSIDERATIONS ON THE MANAGEMENT OF ACCESSIBILITY IMPROVEMENT IMPACT ON LAND-USE
}

\author{
Negulescu Mihaela Hermina \\ 'Ion Mincu' University of Architecture and Urbanism, Faculty of Urbanism \\ (ROMANIA) \\ arh.mihaela.negulescu[at]gmail.com
}

\begin{abstract}
This paper addresses a LUM (Land Use \& Mobility) approach of accessibility improvement issues. It presents a deterministic radiography of the impact that a new transportation infrastructure has within its territory of influence, through the accessibility it provides. The study concludes on legislative and methodological improvements for developing a necessary, integrated LUM planning of accessibility, so as to achieve its highest capitalization and to mitigate its possible negative side-effects in the territory. The focus is on the key issues for developing a framework for a LUM planning of accessibility in the Romanian context.
\end{abstract}

Keywords: Accessibility, LUM (Land Use \& Mobility) planning, Urban planning

\section{INTRODUCTION}

A major challenge for maintaining the spatial, economic, social and environmental balance in the urban evolution process it is today the sustainable management of urban mobility which has become a highly complex system with many negative externalities (pollution, noise, health problems, degradation of public spaces, climate change etc.). In this respect, an important concern, with the utmost relevance for the urban and territorial planning, is the efficient planning and capitalization of accessibility, which can only be achieved in an integrated LUM approach (Land Use \& Mobility planning) ${ }^{1}[1]$

\subsection{ACCESSIBILITY - CONCEPTUAL CLARIFICATIONS}

From an urban planning perspective, the accessibility is the "relational" quality of a territory, not measured only in terms of distance and travel time, but also in terms of cost and comfort of traveling, a comfort that is, inter alia, related to the quality of the traversed spaces. [2]

The accessibility of an area is a "bidirectional" attribute, being both a measure of the possibilities to access various other areas / locations of interest in the rest of the territory (city, metropolitan area, region, etc.), and vice versa, a measure of its reachability from many other areas. "Accessibility can be defined in terms of

\footnotetext{
1 This novel integrated planning approach, derived from the Land Use \& Transportation (LUT) policy, is developed at the "Urban Mobility" Master programme at the School of Urban Planning - "Ion Mincu University of Architecture and Urbanism", Bucharest
} 
potential (opportunities that can be reached) or in terms of activity (opportunities that are reached)." [3]. Consequently, accessibility confers non-topological centrality. [4]

From transportation perspective, accessibility is the purpose and the outcome of transport services. "The ultimate goal of most transportation is access, people's ability to reach desired goods, services and activities." [3], [5]

Accessibility is the result of the road network organization (especially in terms of connectivity), calibration and configuration of the transport systems, and thus relies on expensive infrastructures and services. Therefore, accessibility has/brings high monetary added-value, mostly based on public investments in transport systems.

\section{METHODOLOGICAL ASPECTS}

This paper correlates results of the author's research in several studies ${ }^{2}$, in order to answer the following research questions: 1 . Which is the determinism of urban development dynamics generated by a new, structuring ${ }^{3}$, transport infrastructure and its associated improvement of accessibility? 2. What changes in accessibility planning are necessary for its most efficient capitalization and for limiting the "boomerang" negative effects it can generate in the territory? What changes to the spatial planning framework are needed for properly managing accessibility and the impact of its improvement through a new transport infrastructure?

\section{RESULTS}

\subsection{THE SPATIAL IMPACT OF ACCESSIBILITY IMPROVEMENT THROUGH A NEW TRANSPORT INFRASTRUCTURE - LAND-USE DYNAMICS}

The creation of a new public and structuring transport line in a territory confers to the latter new accessibility attributes related to the characteristics of the new transport service.[6] Depending on the territorial level of the new transport service, the area acquires or improves its accessibility at local, regionalmetropolitan, national or (inter)continental level.

Depending on the level of connectivity, both direct and indirect (with transfer to other lines or means of transportation) with the cities' and FUA's areas of interest that the new public transport (PT) line brings to an area, the later acquires or improves its attribute of "centrality" by accessibility. [4]

The higher the commercial speed of transport is, the longer is the distance traveled in a unit of time (or shorter is the time of travelling a distance) and the served area "approaches" in terms of "distance-time" other areas with which it is directly or indirectly connected through the new transport line.

\footnotetext{
2 Mobility and Urban Form - Negulescu M. (2008) Ph.D. thesis, SAFENET (2016), MODUR(2008), TERITRANS(2007)

3 Transport systems in reserved corridor / track, in particular railways (subway, tramway), which have a high commercial speed

4 FUA - Functional Urban Area is an economic unit consisting of a dense "city core" and its area of influence considered to be the city's "commuting zone" (often coincides with the urban agglomeration or the metropolitan area of a city)
} 
The accessibility provided by the new transport line has a major effect in the stations' "catchment area"- considered to be either the territory within $5^{\prime}$ walking isochronous, either $400 \mathrm{~m}$ radius areas around the stations. New accessibility also spreads within a wider territory - an "influence area" - extending up to 10' walking distance area, or $800 \mathrm{~m}$ away from the stations area. Depending on the distance between the stations of the transport line, the territory that gains increased accessibility is either continuous along the line, either a sum of areas around the stations. Thus, the new line will generate dynamics of development / densification either in "corridor" areas either in concentrated-dispersed areas (concentrated around stations but spaced apart and dispersed in the territory, e.g. such as for the high-speed lines). (Fig.1)

Therefore, the development of a new infrastructure of transport leads to the improvement of the accessibility within its immediate and wider territory of influence, due to the "approaching/proximity" and "centrality" effects. Locating real estate demand augments [6], boosting a fast process of densification and/or of changing the functional profile of the served areas.[8]

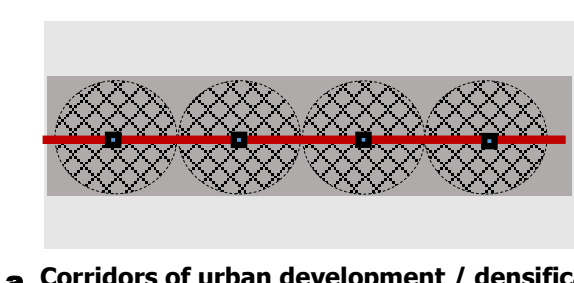

a Corridors of urban development / densification along the transport lines of medium speed (having close stations)

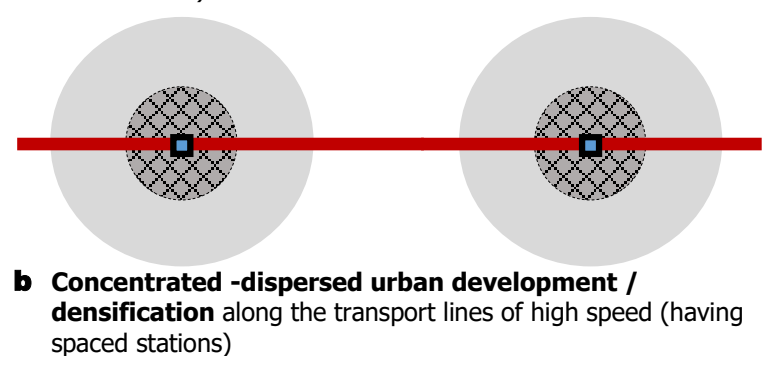

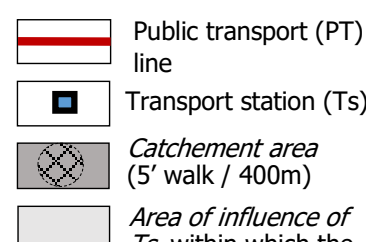

$T S$, within which the demand of localization grows, generating development / densification dynamics

Figure 1 Areas of accessibility diffusion, with urban development/densification dynamics: a. Corridor areas; b. Concentrated - dispersed areas (Author: Negulescu,M.)

The densification dynamics [9] and land use intensity increase (through higher Floor Area Ratio-FAR) evolve in a logic of real-estate profitability, in the context of the land value increase in areas that benefit from the improved accessibility (e.g. around some of the new metro stations occurs replacement dynamics of the lowdensity residential urban tissues with higher buildings, usually higher trafficgenerators. (Fig. 4) [10] 
The change in the functional profile of some areas is determined by the location within them of new activities whose mobility profile generally capitalizes the new accessibility profile of the area. ${ }^{5}$

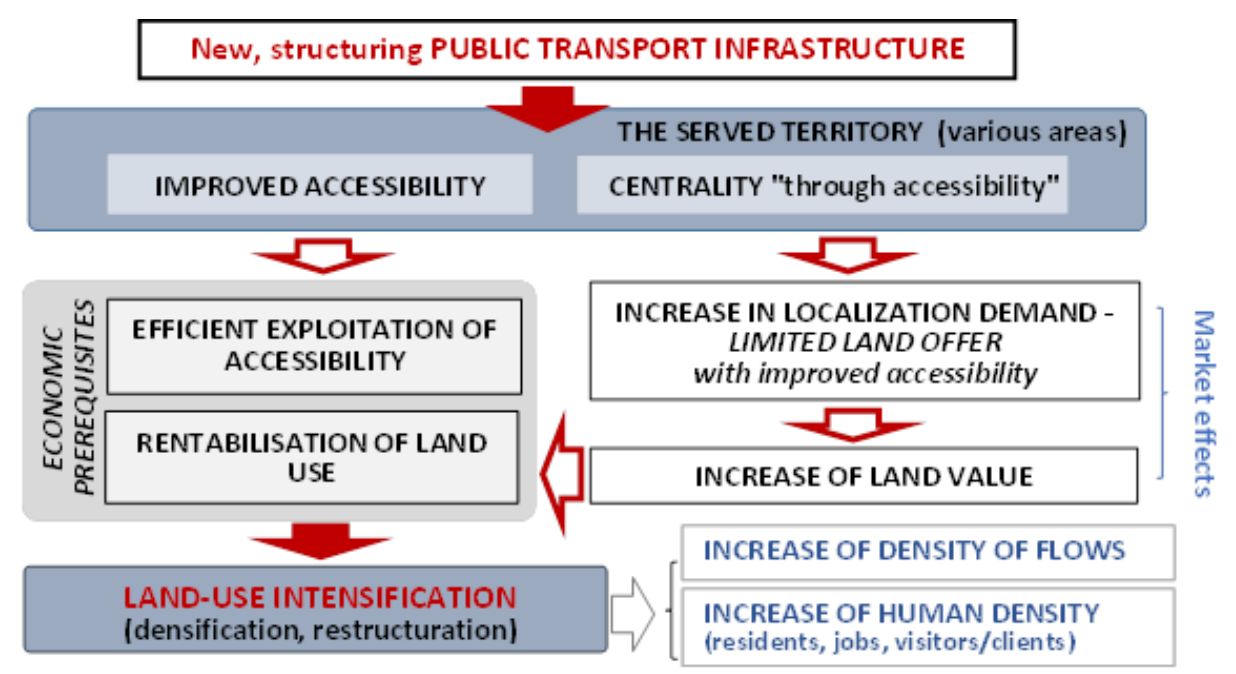

Figure $\mathbf{2}$ The process of land-use intensification in the areas of influences of new (structuring) public transport lines (Author: Negulescu M.)
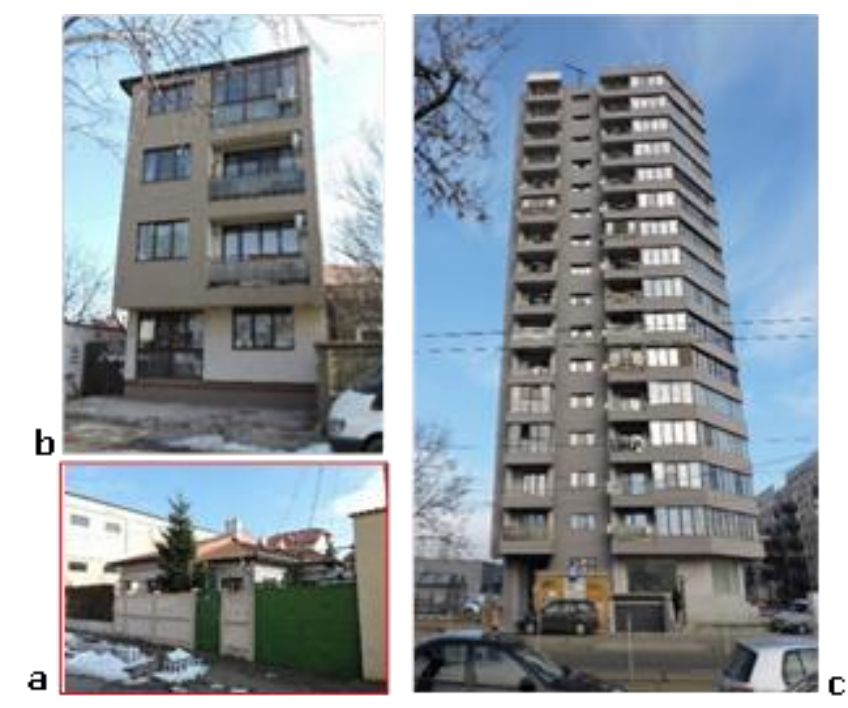

Figure 3 The process of densification and land use intensification (increase of the soil occupancy coefficient-SOC, Floor Area Ratio -FAR), in the territory of influence of M4 metro line extension, in Bucureştii Noi neighborhood (Bucharest) a. The originary low density residential fabric $b$. residential fabric built after the metro line opening; right - c. major increase of land use in the proximity of the new Jiului subway station. (Author: Negulescu,M.)

5 "Mobility profile" and "accessibility profile" concepts refer to the characteristics of activities and (respective) of the sites accessibility, as defined by the ABC policy- see below 
The pressure of these types of changes occurs on the route of a new, structuring public transport line, in various types of urban areas, with various potentials for functional and morphological transformations: "strong" areas - intensively built-up, and impossible to restructure, urban tissue, "weak" areas - with potential for densification / restructuring, abandoned areas (former industrial areas, harbors, military zones) or unbuilt areas. Improving accessibility generates spatial and functional transformations, towards increasing land use [3],[5], that differ relative to the potential for transformation of the areas served by the new transport line: insertions, conversions, densifications, regenerations, restructuring etc.

\subsection{MANAGING THE DYNAMICS OF DENSIFICATION IN THE AREA OF INFLUENCE OF A NEW TRANSPORT LINE}

All of these development dynamics are characterized by increased land use, increased human density (residents, jobs, visitors / customers) and increased flows, most often without any change of the old, small-scale road networks. (fig.5).[11] Without an efficient management of these transformations, through urban planning and mobility planning, it is inevitable to arise inadequate ratios between the new content (increased human density and volume of flows) and the container (the territory, and especially its community components which constitute the urban infrastructure: streets and public space; utilities -gas, water, electricitysupply; education, health infrastructure, etc.). From the perspective of urban mobility, in the cases the road network (container) cannot be developed, extended, adapted to the increased volumes of traffic (content), it results a report of inadequacy between them, manifested in traffic congestion. (fig.4) [10]

Thus, the improvement in accessibility through public transport (new infrastructure), without a "LUM management of the densification" within its area of influence, generates a "boomerang effect" of inaccessibility on the road network. [10]

There are two possible ways for avoiding this negative evolution:

1. limitation of the densification process, through urban planning regulations

2. reorganization of the flows in an appropriate-to-the-container (road network) form, through a new mobility scheme.

The limitation of densification (through the limitation of SOC, FAR) is rarely effective given that, especially in areas that are not "strong", real estate pressure increases significantly and finally leads to the intensification of land use, especially in the context of a derogatory urban planning practice. Also, this option is not pertinent to the best capitalization on the new (expensive) accessibility and it is not justified in areas where the land (whose value increases considerably) is poorly used (e.g. in peripheral districts with small dwellings on large plots, where metro lines are prolonged) (fig.3). 
Therefore, in order to avoid inadequacies between the content and container, the most appropriate solution in most situations is to reorganize the system of travels through a new zonal mobility scheme oriented towards a new modal split of travels so as to achieve a reduction of the space consumed by the multi-modal traffic, a reallocation of the flows on the network, an improvement of the offer for public transport and non-motorized travels, a reorganization of parking offer, etc. (fig.4) These zonal mobility schemes should be oriented towards achieving a low share of car-use and an increased share of less space-consuming and less polluting travels: with public transport, non-motorized travels - on foot or by bicycle, and of the individual travels by vehicles belonging to "public fleets" of the new, trans-modal transport systems: bike-sharing, car-sharing.

Since 2014, urban mobility in Romania is planned through Sustainable Urban Mobility Plans (SUMPS) mostly at the local and FUAs level. [12],[13] Considering the complexity of mobility issues to all the urban levels, mobility schemes must be carefully planned also at the zonal level and at the level of traffic-generating activities that intend to locate in an area. [10] For example, France developed a tool for the management of the flows generated by enterprises with more than 100 jobs: PDE - Le plan de déplacements entreprise, which identifies mobility schemes for the employees, geared towards sustainable travel modes. The authorization for the activities with more than 100 employees is conditioned on the preparation of the PDE.

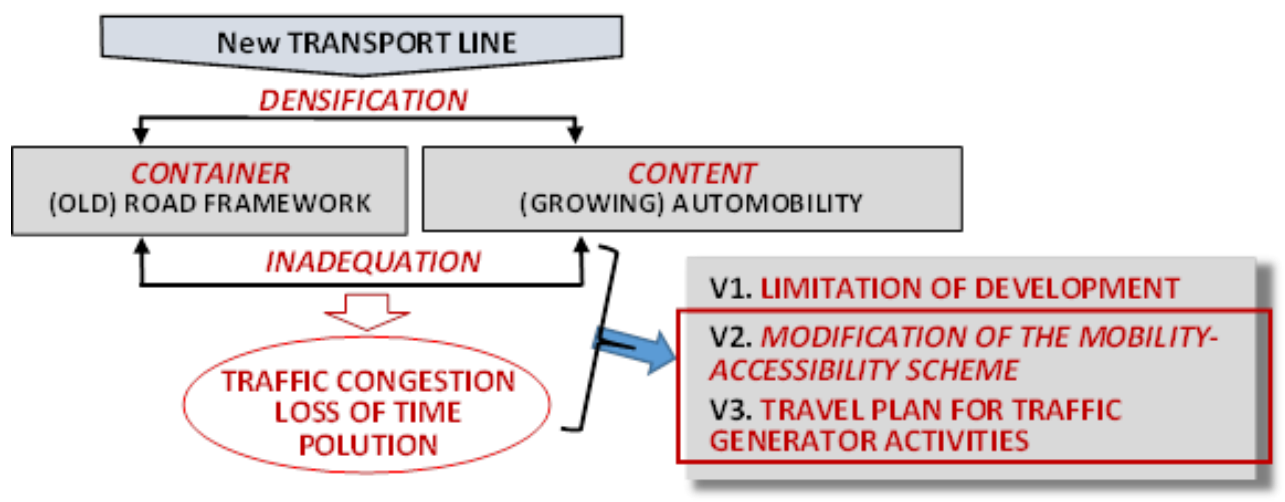

Figure 4 Management of the container-contenant report in the process of urban densification (Author: Negulescu,M., [10])

To make effective use of accessibility [and thus to avoid inadequacies between the container (place / territory) and the content (activities)], Netherlands developed the $A B C$ policy which defined different categories of mobility profiles of activities [14], different site accessibility profiles and rules for the proper correlation of the two types of accessibility features (of places and activities).

Sites are classified by type of accessibility, as follows: site A - high accessibility to collective public transport; site B - relatively good accessibility to public transport and car, site $\mathrm{C}$ - high car accessibility and low accessibility to public transport, $\mathrm{R}$ 
site - low accessibility both with the car and with the public transport. The classification of the mobility profiles of the activities is based on the following criteria: 1 . the intensity of the production process - the number of workers per unit area, 2. the mobility of the employees - the car-dependency of the activities, 3. the intensity of the visits - the number of visitors per unit surface, 4 . dependence on freight.

However, the classifications proposed by the $A B C$ policy do not address the territorial level of the two types of accessibility/mobility profiles. For an efficient use and capitalization of accessibility, it is necessary also to manage a good correlation between the territorial level of accessibility provided by a PT infrastructure and services and the territorial level of the activities catchement areas. Thus, activities that polarize flows at a regional level (e.g. business poles, logistics poles, large city centers, regional public equipment - hospitals, cultural institutions, universities, etc.) or at a national / international level (e.g. notorious business districts, technological parks, important touristic areas etc.) have to be located in relation with regional PT (e.g. subway, regional train, bus), respectively in relation to public transport at national / international level (train, high-speed train on TEN-T). Those apparently obvious requirements are not meet in practice if appropriate regulations are not legally set. (fig.5)
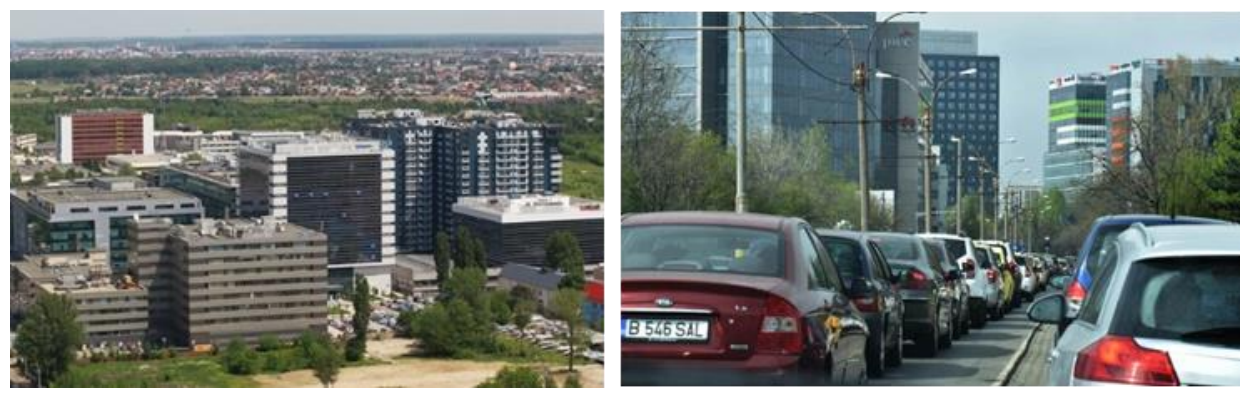

Figure 5 Pipera-Voluntari business district - an eloquent example of intensive urban development unsupported by an adequate planning of accessibility through a zonal mobility scheme. It gathers about 250000 jobs that polarize high volumes of traffic both at local level and at the territorial - regional / metropolitan level. The urban pole is located in an area without good connections especially at the territorial level. This inadequacy between the mobility profile of the activities located within the business district and the accessibility profile of the area generates high accessibility-related dysfunctions (congestion, time costs etc.) Source of the images: left- https://www.retailers.ro ; righthttps://www.cotidianul.ro/traficul-este-infernal-in-pipera-si-in-afara-orelor-varf/

The nodal transport infrastructures integrated on TEN -T (high speed trains railway-stations, airports, ports) are connector-hubs that provide (new) accessibility at national and (inter) continental level. Through this privileged accessibility, the cities and their area of influence (the whole FUAs) - connected to european / international flows of goods and people - get a form of centrality at national and (inter)continental level. The territories that benefit the most from this accessibility are the areas around the long-distance and high-speed transport stations / terminals: railway stations, ports, airports. Within this areas accessibility boosts the fastest and complex urban development, regeneration, restructuring dynamics. [4] 
Thus, the railway stations and especially those on the European rail network (rail TEN-T corridors), become main connector-hubs of the cities FUA's to major highspeed continental flows, and their areas of influence get a "strategic character" due to their privileged accessibility and to their representativeness as international (rail)"gates" of the cities and of their whole areas of influence.

Therefore, the railway stations develop not only their function of intermodal pole, in which the transport networks at the territorial levels are connected with all the local transport networks, but also their hypostasis of "railway urban gate" correlated with that of (secondary) "centrality" for the station's neighborhood and for the whole urban system. [2],[4] The railway stations are rebuilt or included in bigger, multi-functional buildings, their immediate surrounding areas - "railway station's areas" - are reorganized as public spaces with superior aesthetic and functional qualities while, for the maximum capitalization of territorial /continental accessibility, the wider areas of influence - the "railway station's neighborhoods" undergo significant transformations, up to full restructuring processes, becoming (secondary) urban centralities and/or business poles of regional and (inter)national interest, in coherent, representative assemblies, with a very high level of land use. (Fig. 6) These vast urban operations need related complex land policies.
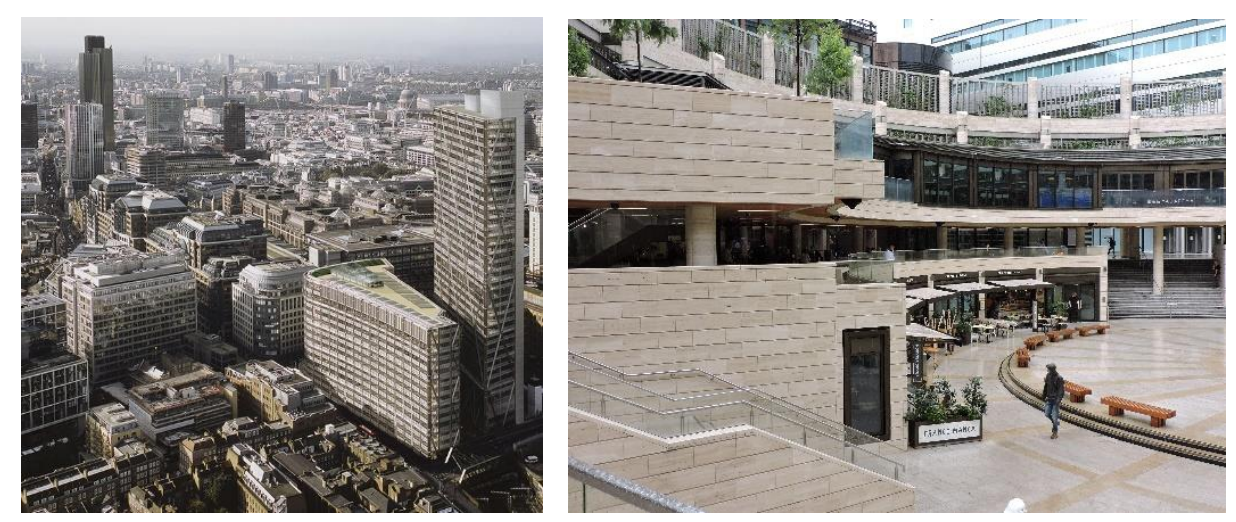

Figure 6 Broadgate district - a mixed use, predominantly business and commercial district of international level, highly dense and representative, which was built in the central zone of London, directly connected to Liverpool Street Station - a main intermodal hub of the city (sources of the images: left - http://www.m3c.co.uk/about-m3/item/70broadgate. html, right - the author)

In Romania, there are several train stations located on (future) high-speed TEN-T railway routes which do not benefit from an early planning of the development of their surrounding areas so that their future hypostasis of "European" stations and the related continental accessibility can be efficiently capitalized, with all the previously mentioned implications (e.g. North Railway Station in Bucharest - fig. 7, North Railway Station Giurgiu etc.)[15],[16],17]. Without an adequate land and land-use policy, in the absence of favorable legislative tools, there is a high risk that a chaotic, uncontrolled building process in the area of influence of these stations waste the possibility to coherently develop complex, coherent and 
representative assemblies when the high speed railway transport will be realized, bringing high international accessibility. (Fig.7)

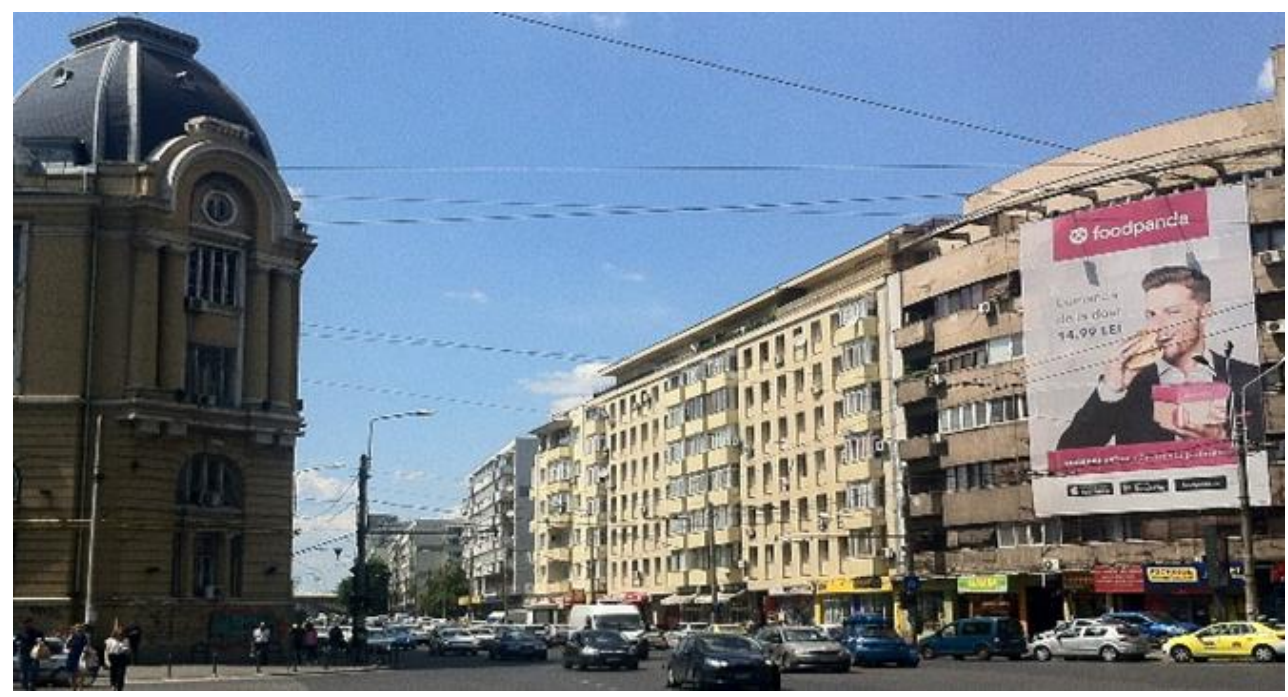

Figure 7 North Railway Station in Bucharest - example of poor capitalization of the territorial accessibility. The area of influence of this main intermodal hub contains, to a considerable extent, a residential fabric that does not need and does not use the complex accessibility at regional, national, continental level (which will improve significantly with the development of the pan-European rail corridor IV); source of the image: Negulescu. M,

\subsection{DIFFUSION OF ACCESSIBILITY WITHIN THE TERRITORY}

In order to capitalize on the new accessibility in a wider area, it is necessary to plan a multimodal accessibility for the new transport stations through very good connections to major road arteries, to local/zonal transport systems and to routes for non-motorized travels (walking, cycling).

A specific feature of the regional/metropolitan transport systems - medium and long distance and medium and high-speed lines - is that they do not have a high level of territorial coverage and connectivity, as those at the city level. However, the accessibility - valuable and expensive - must be disseminated and exploited at the territorial level (FUA/ region), beyond the immediate catchment area of the stations, in a wider area of influence and polarization (the "influence area"). To this end, the regional public transport lines (regional train, tram-train, subway) need to be well connected with complementary, zonal / local feeder systems (other than automobility). The latter have to feed with passengers from a larger territory the regional transport lines, thus increasing their accessibility. The periurban feeder systems for the regional transport should be less car-oriented multimodal systems that in the future will probably include driverless car-sharing schemes.

The new transport stations (generally, but especially on transport lines at the territorial level) should be organized as intermodal nodes, well connected to zonal / local (urban or peri-urban) networks that can diffuse the accessibility: major 
roads networks, local public transport of the localities traversed by the regional PT line. Also, for a good non-motorized accessibility, the stations have to be very well connected to major bicycle lanes that connect them with the main areas of interest. Some of the intermodal stations on regional PT lines should provide park $\&$ ride $(P \& R)$ and bike $\&$ ride $(B \& R)$ facilities, to create the premises for the transfer from the car to the regional-metropolitan transport.

PT stations with high, nodal accessibility should be associated with (sub)urban micro-centralities that harness the high level of connectivity at the territorial level.

An example of poor management of the impact of a new subway line regarding the development dynamics it will generate, but also of the diffusion of the accessibility within the metropolitan territory (northern peripheric and peri-urban areas) is the upcoming M6 subway line, planned for Bucharest city. [18] Its main objective is to connect Aurel Vlaicu Airport (Otopeni) with the capital-city Bucharest, but it will also considerably improve the accessibility of the northern part of Bucharest FUA.
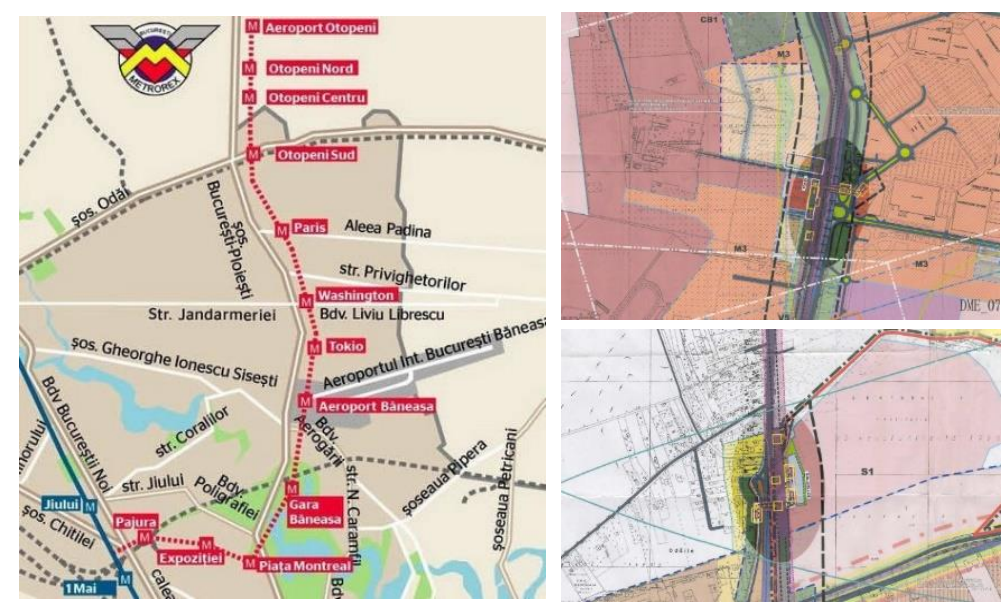

Figure 8 The M6 subway line; left: route and stations; right: stations with insufficient motorized and non-mototrized connections in the surrounding area, with "undiffused" accessibility, source: [19]

The way this line will generate development dynamics has not been studied in any strategy and in any territorial or urban development plan. The only urbanistic approach of the new transport line is in the PUZ (Zonal Urban Plan) "MAGISTRALA 6: 1MAI - OTOPENI, TRONSON 1, SECTOR 1", which studies and regulates only the route of the line and the location of the metro stations. (Fig. 8) There is no approach of the way the new accessibility will be difussed in the territory from the subway stations. It is neither addressed the hypostasis of intermodal points of the stations, and neither the issue of the park\&rides and bike\&ride facilities at some of the stations, for the transfer from the car to the subway. Thus, in the absence of a coherent vision and planning of the development dynamics that undoubtedly will be generated by M6 subway line, and without a land-policy for strategical developments serving the public interest, a rather chaotic building process can be anticipated around the new stations. That will waste the (land) opportunities to create in the future new connections of the stations in the territory as well as to master an efficient land-use of the areas around them which directly benefit from the valuable accessibility. Also, the high added-value of accessibility, which is the result of consistent public investments, will go only to private landowners. 
This example is highly relevant regarding the lack of methodological and legislative framework for the proper planning and capitalization of accessibility in the Romanian urban planning practice. Though the new tool recommended by EC for urban mobility planning (SUMP) puts a higher emphasis on the spatial planning insight, the emerging LUM logic is still weak and it is not served by an appropriate implementation framework.

\section{CONCLUSIONS - MILESTONES FOR THE IMPROVEMENT OF THE ACCESSIBILITY PLANNING FRAMEWORK, TOWARDS A LUM APPROACH}

Mobility planning in Romania currently moves from stage 1 (planning for vehiclesroad building) to stage 2 (planning for people -better public transport) of the Transport Polycy Development Cycle. [20] The paradygm change involves systemic evolutions of the conceptual framework, planning practice and of the implementation framework. Multimodal accessibility is a central issue of these evolutions.

\subsection{LUM PLANNING}

Accessibility must be effectively planned and capitalized through a LUM (Land Use \& Mobility) approach, supposing a (much) better coordination of spatial development planning with transport development planning in a bidirectional logic:

$\rightarrow$ Spatial planning must be explicitly and methodically oriented towards:

$\circ$ 1. Effective capitalization of accessibility provided by transport networks

- 2. Creating spatial premises for multimodal accessibility.

$\rightarrow$ The mobility offer must be (re)organized so as to provide multimodal and contextualised accessibility to the built areas (with priority for high density areas, main traffic generators). Sustainable Urban Mobility Plans must set policies, projects and measures that meet both the exigency of accessibility and the need for public space and urban life quality, through a more sensitive to the urban context planning of mobility.

\subsection{CAPITALIZATION OF ACCESSIBILITY AND THE MANAGEMENT OF ITS IMPACT ON URBAN DEVELOPMENT}

Urban and territorial development strategies and plans have to (early) study, plan and regulate the spatial development in the areas of influence of the future new transport infrastructure (road arteries, public transport, intermodal poles, etc.) which, through the new accessibility they provide, boost development / densification / restructuring dynamics.

Also, spatial development should not be permitted anymore without good accessibility to public transport and other alternatives to the private car modes of transport (e.g. bicycle, car-sharing), for avoiding the car-dependency of the new areas. To this end, Tranzit Oriented Devlopment (TOD) specific regulations should be developed in the Romanian spatial planning framework. 
It is necessary to achieve a very good use of accessibility through a rational spatial development planning, oriented towards:

- Regulation of the land use in the area of influence of a new transport infrastructure so as to achieve a proper correlation between the mobility profile of the activities and the new accessibility profile of the area.

- Regulating intensive land use around the nodal transport stations which provide privileged accessibility (very good local connections and / or connections at the territorial level)

- Correlation of nodal transport stations that provide high, complex accessibility with:

- urban or periurban macro or micro-centralities which effectively use the stations' connections in the territory

- representative business / mixed poles that harness of territorial accessibility (regional, national, continental)

- Dissemination of the accessibility provided by higher-speed transport in a wider territory the good connection of the station to the major road network to the cycling network, other transport networks (including transmodal ones - e.g. car-sharing). It is the case of the regional (rail) transport lines, but also of the local structuring transport lines - subway, tramway- whose networks have a low territorial coverage in peripheral and periurban areas.

\subsection{NEW TOOLS FOR MANAGING AND CAPITALIZING ON ACCESSIBILITY}

It is necessary to develop methods for a more accurate and explicit correlation between the mobility profiles of activities (accessibility needs) and the accessibility profiles (mobility offer) of places, in the spatial planning process. An example of a spatial policy focused on good accessibility management is the $A B C$ policy (Netherlands).

It is necessary a tool for managing the system of travels determined by the location of traffic generator activities in different places. E.g. such tools are the "Plan de déplacements entreprise" (France), and (green) Travel plans (UK).

Currently, at the zonal level, the planning of urban development is conceived and regulated through PUZs (Zonal Urban Plans) with a limited component of "circulation study" focusing mainly on road accessibility. It is necessary to revise the PUZ planning tool in a more integrate LUM perspective so as to become an Urban Planning and Zonal Mobility Plan ("PUMZ"). „PUMZ" must include a more comprehensive zonal mobility scheme that systemically manages the mobility offer for all types of travels, in order to provide a multimodal accessibility to the studied zone: motorized accessibility (by public transport, by car) as well as non-motorized accessibility (pedestrian or bicycle). 
For the achievement of coherent (re)developement / restructuring operations in the areas of influence of nodal transport infrastructures (e.g. intermodal points at European level) it is necessary to develop an adequate legislative framework for complex land policy and regulation that should allow:

preservation of the potential for (re)construction and development of representative, coherent built assemblies, considering that such complex operations often are realized in a (very) long time horizon, with a long delay after the strategic planning phase.

capitalizing the new accessibility (resulting from high public investments) in the interest of the community, in the areas that acquire added-value and "strategic character" due to the new public transport infrastructure (the areas around the main stations whitin which it is desirable to create micro-centralities and/or representative urban ensembles).

\section{REFERENCES}

[1] Negulescu, M.H. (2008), "Theoretical milestones for an urban planning with premises for a sustainable mobility, in coordination with transports planning, in: Proceedings of "TRANSLU 10"-Transportation and land use interaction" international conference, Politehnica University, Bucharest; also in: Buletinul AGIR, An XVII, nr.Supliment 1/2012

[2] Negulescu, M.H. (2011), "Mobility and urban form - theoretical aspects," "Ion Mincu" Academic Publishing House, Bucharest

[3] Litman, T. (2017), "Evaluating Accessibility for Transportation Planning, Victoria Transport Policy Institute site (acc. march 2018), http://www.vtpi.org/access.pdf

[4] Negulescu, M.H. (2008), "Mobility and Urban Form" ["Mobilitate și formă urbană"] - Ph.D. thesis, "IonMincu" University of architecture and Urban Planning. [5] Raicu, Ş., Popa,M.,(2009) "Transports and Territorial Planning - Accessibility and attractivity",in: AGIR Journal no. 4/2009, http://www.agir.ro/buletine/496.pdf

[6] Raicu. R., Raicu. S, Costescu. D, Popa. M. (2014), "Predictive Models for Routing in Urban Distribution", Edited by: Taniguchi, E; Thompson, R.G., the 8th International Conference on City Logistics, Procedia Social and Behavioral Sciences, 125 (2014), pg. 459-471 DOI:10.1016/j.sbspro.2014.01.1488, (ISI)

[7] Boucq E., Papon, F. (2008) Assessment of the real estate benefits due to accessibility gains brought by a transport project: the impacts of a light rail infrastructure improvement in the Hauts-de-Seine department", in: European Transport|Trasporti Europei no. 40/2008,

http://www.istiee.org/te/papers/n40/3_def_boucqpapon.pdf

[8] Negulescu, M.H. (2007), "Railway urban transport - tool for urban development and rehabilitation", paper presented at "Rail transport - urban development driver" conference, published in Club Feroviar (Railway PRO) no.8 / 2007.

[9] Hansen, W.G. (1959), "How Accessibility Shapes Land Use", Journal of the American Institute of Planners. Vol. 35, No. 2. 
[10] Negulescu, M.H. (2018), "Traffic generators localization - (new) tools for managing the accessibility in urban planning", NOVEMBArh architects Hackaton, Bucharest

[11] Popa, M; Raicu, S; Rosca, E; Costescu, D. "Optimal planning for developing, modernizing and maintaining the street infrastructure of dense and large urban areas", Edited by: Brebbia, CA, URBAN TRANSPORT XIII: URBAN TRANSPORT AND THE ENVIRONMENT IN THE 21ST CENTURY, WIT TRANSACTIONS ON THE BUILT ENVIRONMENT, Vol. 96, pg.: 471-480, (ISI)

[12] Wefering F., Rupprecht S., Bührmann S., Böhler-Baedeker S. (2011). "SUMP Sustainable Urban Mobility Plan Guidelines - Developing and Implementing a Sustainable Urban Mobility Plan", EU- Intelligent Energy Europe Programme, http://www.eltis.org/guidelines/sump-guidelines

[13] European Commission, (2013), "Urban mobility package"

[14, Martens, M.J., Griethuysen, S., "The ABC location policy in the Netherlands The right business at the right place ", in: website Technico Lisboa (last accessed April 2018) https://fenix.tecnico.ulisboa.pt/downloadFile/3779572236303/abc.pdf

[15] Politehnica University\&all (2008), "MODUR - Promoting sustainable mobility IN BUCHAREST". Excellence research Program, Romanian Ministry of Education and Research, http://ingtrans.pub.ro/content/MODUR.html

[16] Negulescu, M.H. (2014), "Infrastructure of transports and policy of mobility", Strategic concept for Bucharest 2035, in: Urbanismul (Urban Planning) Journal no. 16-17/2014, http://www.csb2035.ro

[17] Budapest University of Technology and Economics (BUTE) \& all. on-going untill 2019. "DANUrB - DANube Urban Brand", Interreg- Danube Transnational Programme, http://www.interreg-danube.eu/approved-projects/danurb

[18] Sustainable Urban Mobility Plan Bucharest-Ilfov, (2015), PMB (Bucharest City hall) website, last accessed April 2018

[19] Zonal Urban Plan (PUZ) "MAGISTRALA 6: 1MAI - OTOPENI, TRONSON 1, SECTOR 1", PMB (Bucharest City hall) website, last accessed April 2018

http://www4.pmb.ro/wwwt/institutii/CGMB/sedinte/ordinea_de_zi/db/04_2016092 9.pdf

[20] University College London (UCL)\&all, (2018), CREATE - research project, Horizon 2020 programme -European Union, http://www.create-mobility.eu/

Article distributed under a Creative Commons AttributionNonCommercial-NoDerivatives 4.0 International License (CC BY-NC-ND).

Received: April 20, 2018

Accepted: May 24, 2018. 